Proceedings

\title{
Solar Thermal Technologies for Low-Carbon Industrial Processes: Dynamic Modelling, Techno-Economic Analysis and Environmental Impact ${ }^{+}$
}

\author{
Michele Bolognese ${ }^{1, *}$, Luigi Crema ${ }^{1}$, Prattico Luca ${ }^{1,2}$, Diego Viesi ${ }^{1}$ and Ruben Bartali ${ }^{1}$ \\ 1 Fondazione Bruno Kessler, Via Sommarive 18, 38123 Povo, Trento, Italy; crema@fbk.eu (L.C.); \\ luca.prattico@uniroma1.it (P.L.); viesi@fbk.eu (D.V.); bartali@fbk.eu (R.B.) \\ 2 Sapienza University of Rome, Via Eudossiana 18, 00185 Rome, Italy \\ * Correspondence: mbolognese@fbk.eu \\ + Presented at the First World Energies Forum, 14 September-5 October 2020; Available online: \\ https://wef.sciforum.net/.
}

Published: 11 September 2020

\begin{abstract}
Solar thermal technologies are already available on the market, and they are robust and relatively cheap. Unfortunately, solar heat is seldom used in the industrial processes, and the main obstacle of solar heat diffusion is often the lack of adequate predictive modelling of solar plant integration that identifies its energy potential, economic feasibility, and environmental benefits. In this paper, we aim to investigate and evaluate the possibility of supplying solar heat to the pastadrying process located in the northeast of the Italian Alps ("Felicetti"). The methodology proposed is structured with the combination of several software, namely, PVGIS ${ }^{\circledR}$, Matlab ${ }^{\circledR}$, Dymola $^{\circledR}$. The methodology developed is tested, considering solar thermal energy as the primary source, in different geographical contexts.
\end{abstract}

Keywords: solar heat for the industrial process; predictive dynamic modelling; flexible methodology

\section{Introduction}

Thirty billion tons of carbon dioxide are emitted yearly in the atmosphere of the Earth, and this is causing global warming and drastic climate changes. Average global temperatures have risen $1{ }^{\circ} \mathrm{C}$ above pre-industrial levels and, at current rates of warming, are projected to reach $1.5^{\circ} \mathrm{C}$ within two decades [1]. Therefore, it is urgent to plan small- and large-scale decarbonization interventions. The use of alternative eco-sustainable and carbon-free technologies for the generation of electrical and thermal energy is now a compulsory and conscious choice [2]. Solar thermal technologies are consolidated at economically attractive prices. The total carbon-free solar thermal energy should be a cornerstone of the current energy transition. The industrial sector uses more energy than any other end-use sector [3], and in Europe, it covers the $22.8 \%$ of total energy demand [3], with $71 \%[4,5]$ accounting for heat demand.

Solar heat has enormous potential for several industrial processes but is still mostly unused [6,7]. This potential depends firstly on the amount of solar radiation available. This is an unpredictable variable depending on several factors, such as the location of the place, cloudiness, air mass etc. Moreover, a careful analysis and industrial process characterization in terms of thermal energy demand and process temperature profile is crucial to also achieve adequate integration of solar process heat. Worldwide, 152 operating plants provide solar process heat for industrial purposes, with more than $140,600 \mathrm{~m}^{2}$ of solar collectors and power of about $100 \mathrm{MWth}$ [8]. Most of the industrial 
heat is required at low to medium temperatures, with temperature below $250{ }^{\circ} \mathrm{C}$ [9] in processes such as sterilization, drying, hydrolysis, distillation, washing, cleaning, evaporation and polymerization [10]. Several applications for the integration of solar heat in industrial processes have been developed: applications of a solar drying system for agro-food industries [11,12] such as pasta [13,14] and tomatoes [15]; for the manufacturing of clay bricks and tiles [16]; and for the meat [17] and dairy industries [18]. In the IEA SHC Task 49 [8], two types of integration are identified: supply level and process level [8]. The supply level integrations differ according to the heat transfer fluid (steam or liquid) used and according to the application, whereas the process level integrations differ according to the way of exchanging heat.

Unfortunately, solar energy is a discontinuous source of energy, and for this reason, it is not easy to match with industrial processes that require energy on demand. However, as reported by many authors $[13,16,18]$, this problem can be overcome by using dynamic predictive models to study and analyze the potential of solar heat integration. Many research works are based on modelling of the solar plant using Transys ${ }^{\circledast}$ as software, and solar plants located in highly irradiated places such as Sicily, Indonesia, and Morocco. In this work, the authors propose a methodology approach based on the synchronized use of different simulation tools, modelling and comparing the potential of the integration of solar heat in the new pasta factory headquarters in Molina (Trento Area), and a hypothetical one in Palermo. A 100\% renewable solution was found considering the land use and performance of the three investigated solar collector technologies. Finally, the use of Dymola ${ }^{\circledR}$ has made it possible to verify the flexibility and dynamic capacity of the solar field adaptation to intermittent variations of solar radiation. An adequate control system was, therefore, necessary to govern the proper operation of the system. The considered industrial process is a real case study of the pasta-drying process. In the first part of the manuscript, the utilized methodology scheme that shows the different steps and information used to build the model is reported. In the second part, there is a detailed description of each step.

\section{Methodology}

The industrial process considered is a real case study of a pasta drying process at the Felicetti Pasta Factory. The production site is historically located in Predazzo, while a new plant will be built in 2021 in the location of Molina di Fiemme. These two locations are situated in the northeast Italian Alps, and they are characterized by a complex topography of ground, which affects the amount of solar radiation available at ground level mainly in the winter months when the solar elevation is lower. In this study, we want to propose a new methodology whose scheme is shown in Figure 1, which compares the potential of solar integration and the relative land use in a low-irradiated and complex topography location such as Molina and in a high-irradiated and simple topography location such as Palermo in the south of Italy.

The two locations were studied separately, considering the different geographical coordinates. The time series of a typical meteorological year (TMY) from 2007 to 2016 by PVGIS [19] are used for solar radiation and air temperature in Molina and in Palermo. The data collections used are the hourly series of DNI (direct normal irradiance), GHI (global horizontal irradiance), and environmental air temperature. Subsequently, three solar collector technologies were considered using data related to the efficiency, size and incidence angle datasheets of three commercial companies, such as Soltigua [20] for parabolic through collectors (PTC), Industrial Solar [21] for linear Fresnel reflectors (LFR) and Kloben [22] for compound parabolic collectors (CPC). In the coefficients used for calculating efficiency are shown (Table 1).

Table 1. In the coefficients used for calculating efficiency.

\begin{tabular}{cccc}
\hline Type of Collectors & $\mathbf{c}_{\mathbf{0}}$ & $\mathbf{a}_{\mathbf{1}}\left(\mathbf{W} / \mathbf{m}^{\mathbf{2}} \mathbf{K}\right)$ & $\mathbf{a}_{\mathbf{2}}\left(\mathbf{W} / \mathbf{m}^{\mathbf{2}} \mathbf{K}^{\mathbf{2}}\right)$ \\
\hline PTC & 0.747 & 0.64 & - \\
LFR & 0.635 & 0.0265 & 0.00043 \\
CPC & 0.718 & 1.051 & 0.004 \\
\hline
\end{tabular}




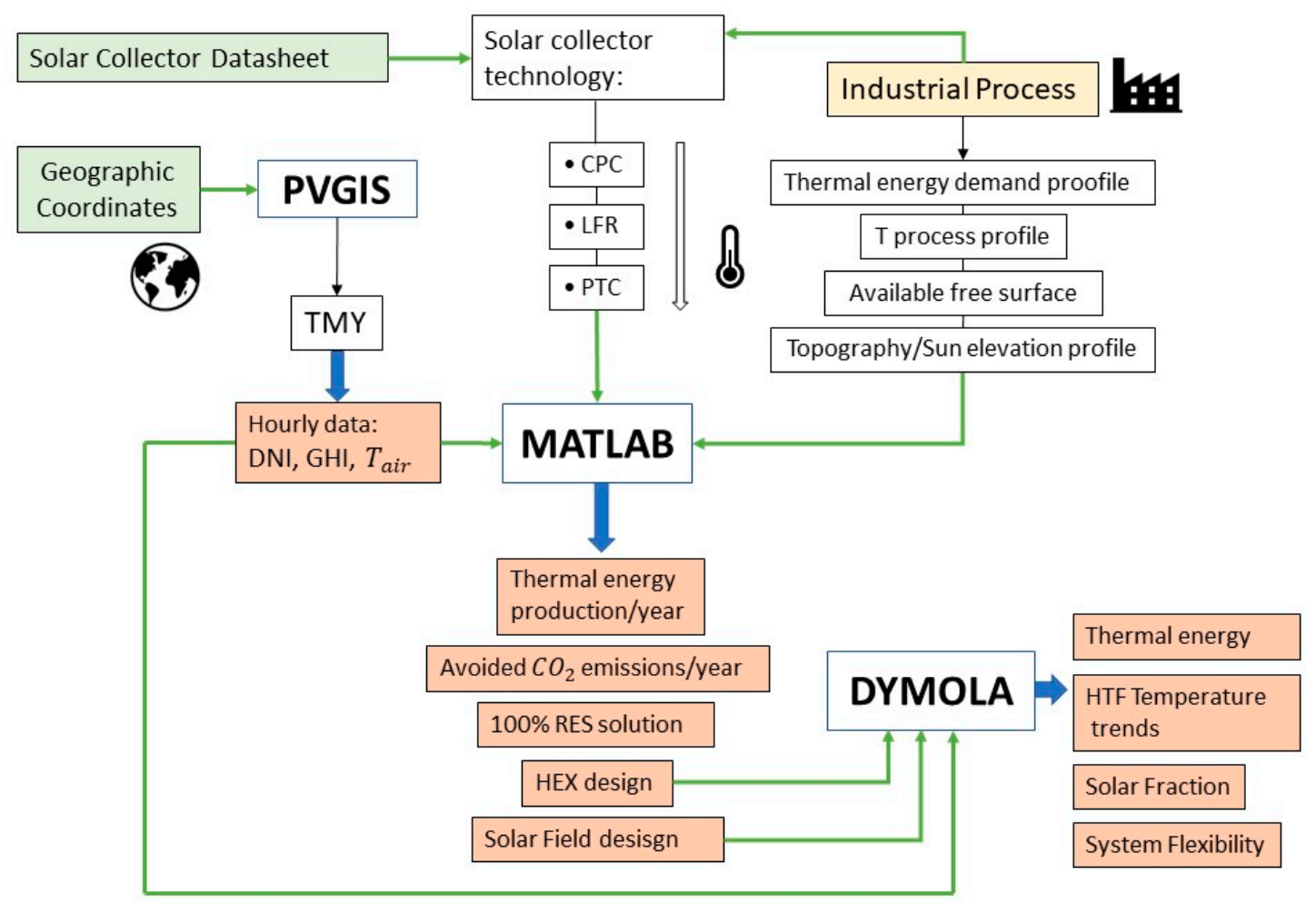

Figure 1. Methodology scheme.

In Table 2, the three solar thermal collectors are presented in terms of sun-tracking technology and land use, which is defined as the ratio of total net area to the gross area used.

For the PTC and LFR technology to work correctly, usually, 1-D sun tracking with north-south orientation is used, whereas the CPC is stationary technology that can be tilted in order to optimize the thermal energy production.

Table 2. Technology and land use of the three solar thermal collectors used in examination.

\begin{tabular}{ccc}
\hline Type of Collectors & Technology & Land Use (\%) \\
\hline PTC & Tracking 1-D & $42 \%$ \\
LFR & Tracking 1-D & $66 \%$ \\
CPC & Stationary-tilted & $60 \%$ \\
\hline
\end{tabular}

It should be noted that the parabolic tracking of PTC collectors requires more space between rows than what is necessary for LFR collectors. In the specific case of CPC, on the other hand, the proper distance was calculated in order to avoid self-shading phenomena considering an optimal tilt angle of 37 degrees. Moreover, the three technologies present different values of longitudinal $\left(\mathrm{K}_{\mathrm{l}}\right)$ and transversal $\left(\mathrm{K}_{\mathrm{t}}\right)$ incident angle modifiers. These are calculated as polynomial functions of longitudinal $\left(\theta_{l}\right)$ and transversal $\left(\theta_{t}\right)$ components of angle of incidence, interpolating the values present in the solar collector datasheet. The components of the angle of incidence are defined as follows [13]:

$$
\begin{gathered}
\theta_{t}=\arctan \left(\sin \left(\gamma_{s}\right) \tan (\theta)\right) ; \\
\theta_{l}=\arctan \left(\cos \left(\gamma_{s}\right) \tan (\theta) \cos \left(\theta_{t}\right)\right)
\end{gathered}
$$

In which $\gamma_{s}$ is the azimuth angle and $\theta$ is the zenith angle, which is the complementary angle of the sun elevation angle $\left(\alpha_{s}\right)$ and depends on a number of hourly parameters, such as the hourly angle $\mathrm{h}$, the latitude $(\phi)$ and the declination angle $(\delta)$, as shown in the following equations:

$$
\begin{gathered}
\alpha_{s}=\arcsin (\sin (\phi) \sin (\delta)+\sin (\phi) \sin (\delta) \sin (h)) ; \\
\gamma_{s}=\arcsin \left(\frac{\cos (\delta) \cos (h)}{\cos \left(\alpha_{s}\right)}\right)
\end{gathered}
$$


The industrial process characterization is based on the drying process of pasta that requires a large amount of thermal energy. Super-heated water at $135{ }^{\circ} \mathrm{C}$ is used to guarantee adequate temperature and humidity conditions in four different drying tunnels. Each tunnel is used for a specific shape of pasta. The thermal energy is necessary to progressively reduce the fraction of water contained in the pasta until it reaches a rate below 12.50\% [23], which is imposed by law (DPR 9.2.2001 No. 187). The production process is continuous, $24 \mathrm{~h}$ a day. The average net production of pasta is $2730 \mathrm{~kg} / \mathrm{h}$, leading to a total annual production of 19,500 tons. The total thermal demand of the company is $6.69 \mathrm{GWh} /$ year, while the total electrical demand is $3.81 \mathrm{GWh} /$ year. The thermal demand is satisfied by two gas boilers (each of $2000 \mathrm{~kW}$, efficiency: $90 \%$ ) and a gas cogenerator (450 kWth and $460 \mathrm{kWel}$ ). With $4.73 \mathrm{GWh} /$ year, the two boilers cover about $70 \%$ of the company's heat requirements, as shown in Figure 2. In contrast, the remaining part is covered by a combined heat and power system (CHP), which operates continuously, generating simultaneously $1.96 \mathrm{GWh}$ th/year of heat and 3.12 GWhel/year of electricity, thus covering about $82 \%$ of the electricity demand.

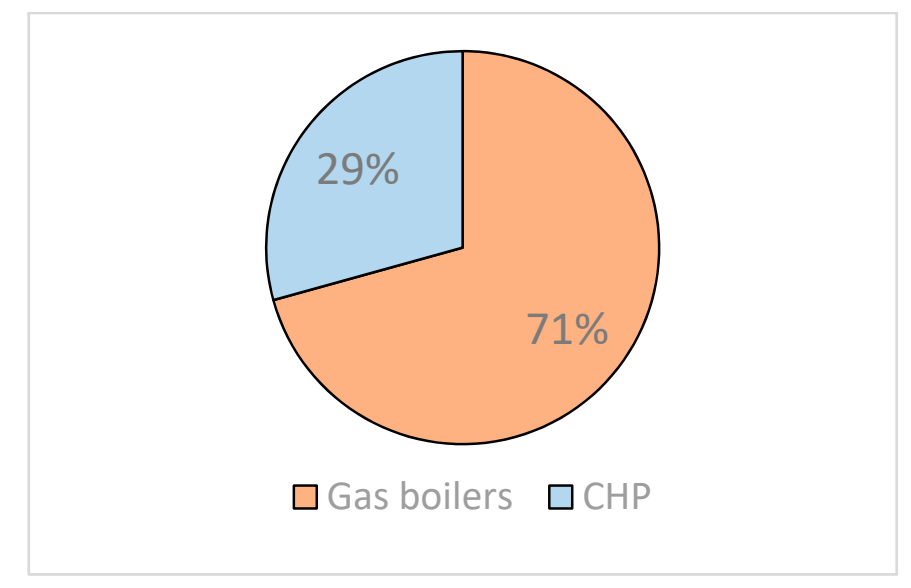

Figure 2. Yearly total energy consumption of the pasta factory.

With an hourly analysis performed in MATLAB, the thermal power was calculated as follows:

$$
Q_{s f}=A_{g} I_{h}\left[K_{\theta} c_{0}-a_{1}\left(T_{e s}-T_{a m b}\right)-a_{2}\left(T_{e s}-T_{a m b}\right)^{2}\right]
$$

in which $\mathrm{Ag}$ is the total net surface of the different solar field; $K_{\theta}$ is the product of $K_{l}$ and $K_{t} ; T_{a m b}$ is the environmental temperature of the respective location obtained from TMY via PVGIS; $I_{h}$ is the hourly solar radiation consisting of DNI for tracking $1 \mathrm{D}$ technologies and GHI for CPC; and $c_{0}, a_{1}$ and $a_{2}$ are the coefficients used for the calculation of efficiency. In particular, the PTC technology is independent from $K_{t}$, which assumes a unit value. Therefore, it performs better in terms of overall efficiency.

Finally, MATLAB ${ }^{\circledR}$ was also used for the adequate design of the heat exchanger (HEX) and the solar field hydro-dynamic parameters that are the necessary inputs for the subsequent dynamic modeling in Dymola. The idea was to integrate solar heat into the pressurized water heating loop of the conventional thermal energy system. The industrial water loop used in this assessment consists of an operating temperature of $135{ }^{\circ} \mathrm{C}$ and a return temperature of $125{ }^{\circ} \mathrm{C}$. The objective of the simulation was to see how this integration works, with the interface of the solar loop consisting of the use of a commercial Therminol SP [24] diathermic oil, and with the water loop positioned through a suitable tubular heat exchanger. The design of the HEX was based on the calculation of a series of geometrical and fluid thermo-dynamic parameters, as shown in Table 3, considering the turbulence conditions concerning the number of Re and Pr exposed by the Dittus-Boelter correlation [25] and considering a Therminol SP loop based on a temperature of $185-155{ }^{\circ} \mathrm{C}$. The thermodynamic properties of the heat thermal fluid (HTF), such as specific heat or viscosity, were considered as polynomials in the function of the fluid temperature [25,26]. In addition, a $\Delta \mathrm{T}$ of $30^{\circ} \mathrm{C}\left(185-155^{\circ} \mathrm{C}\right)$ allows the design flow rate to be calculated in a completely turbulent regime. Therefore, a design flow rate of approximately $5.16 \mathrm{~kg} / \mathrm{s}$ was calculated. Subsequently, considering a thickness 
appropriate to the commercial pipes under consideration, the number of tubes (nt) inside the tubular heat exchanger was calculated, as demonstrated in Figure 3.
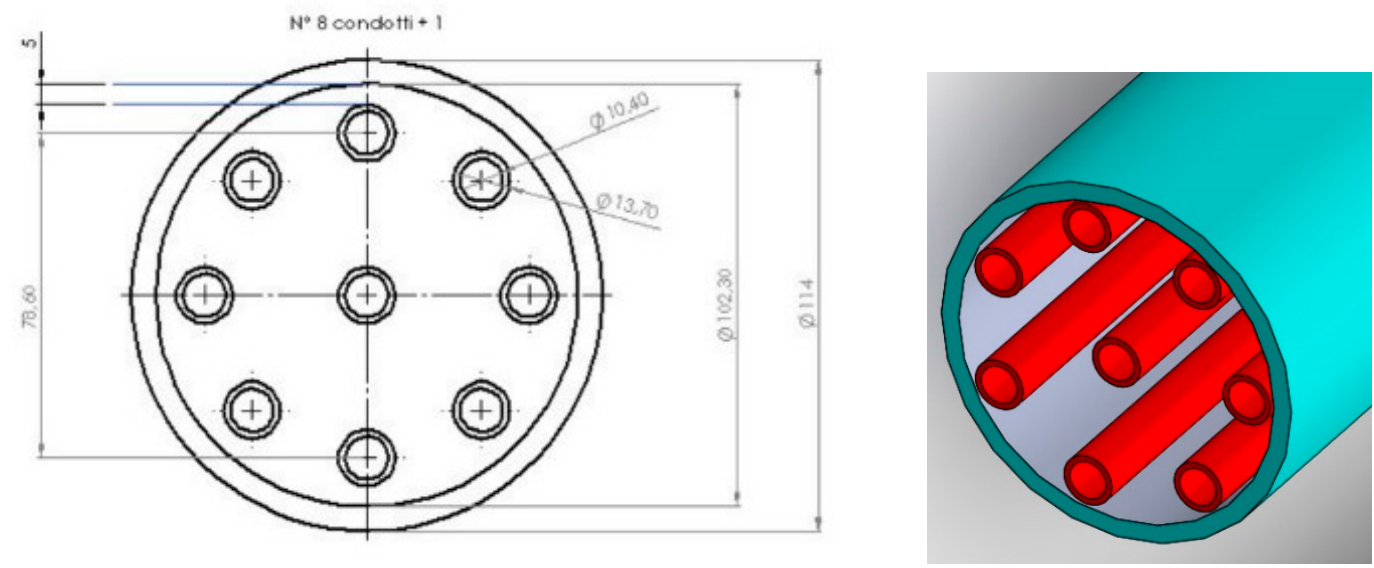

Figure 3. Heat exchanger (HEX) design.

The internal convection coefficient $h_{i}$ (Therminol SP side) is calculated according to the internal diameter with equation $\left(N u=\frac{h}{\lambda d}\right)$, while the external convection coefficient, $h_{e}$ (water side), is calculated in the function of the hydraulic diameter. Therefore, considering a thermal conductivity of $\lambda_{\text {inox }}$ steel of $15 \mathrm{~W} / \mathrm{mK}$, the overall transmission coefficients, referred to as the internal (Ui) and external(Ue) surface as a function of the respective convection coefficients, are calculated. Finally, the geometrical parameters, such as the internal surface (Ai), external surface (Ae) and length (L) of the HEX, were found according to a design of thermal power, considering a $90 \%$ efficiency of heat exchange. The volumes of the exchange mediums, Therminol SP (Vsf) and water (Vwf), and the volume of the metal were also found to be dependent on the geometric parameters. The total metal mass of the HEX was calculated considering a constant density of steel equal to $7980 \mathrm{~kg} / \mathrm{m} 3$ (ANSI B36).

Table 3. Geometrical and fluid thermo-dynamic parameters of the HEX.

\begin{tabular}{cccccc}
\hline \multicolumn{5}{c}{ Geometrical Parameters } \\
\hline $\mathbf{A i}\left(\mathbf{m}^{2}\right)$ & $\mathbf{A e}\left(\mathbf{m}^{2}\right)$ & Metal Mass $(\mathbf{k g})$ & $\boldsymbol{V}_{\boldsymbol{w f}}\left(\mathbf{m}^{3}\right)$ & $\boldsymbol{V}_{\boldsymbol{s f}}\left(\mathbf{m}^{3}\right)$ & $\mathbf{L}(\mathbf{m})$ \\
\hline 3.32 & 4.37 & 175 & 0.058 & 0.0066 & 8.56 \\
\hline \multicolumn{7}{c}{ Fluid Thermo-Dynamic Parameters } \\
\hline $\mathbf{Q}_{\text {nom }}(\mathbf{k W})$ & $\mathbf{n t}$ & $\mathbf{R e}$ & $\boldsymbol{P r}$ & $\mathrm{Ui}\left(\mathbf{W} / \mathbf{m}^{2} \mathbf{K}\right)$ & $\mathrm{Ue}\left(\mathbf{W} / \mathbf{m}^{2} \mathbf{K}\right)$ \\
\hline 377 & 9 & 49239 & 23.32 & 2761 & 2097 \\
\hline
\end{tabular}

The heat exchanger geometry and dimensions are highly influenced by the design of the exchange temperature. It can be noted that a tubular heat exchanger of $8.56 \mathrm{~m}$ has a weight of $175 \mathrm{~kg}$. In order to minimize the space occupied, these types of heat exchangers have the possibility to possess coil-type configurations. These parameters will be used as input in the dynamic simulation in Dymola ${ }^{\circledR}$, whose simulation scheme is presented in Figure 4.

In the case of the Felicetti pasta factory, solar heat is integrated in the water loop that supplies the gas boiler, which is characterized by a moss flow rate of $15 \mathrm{~kg} / \mathrm{s}$ and an input and output temperature of 135 and $125^{\circ} \mathrm{C}$, respectively. With the counter flow tubular heat exchanger (HEX), it is possible to distinguish the solar loop in which the Therminol SP circulates (on the left) and the water loop (on the right) that feeds the industrial process. Localized pressure drops are considered in each component of the system as constant, while the value of distributed pressure drops inside the pipes is proportional to the mass flow rate. Considering the limited available space, a small volume of the tank proportional to the flow rate of about $8 \mathrm{~m}^{3}$ was considered. A series of PIDs that regulate the pump and the closing-opening of the three valves located at the solar field is set to a temperature of $185^{\circ} \mathrm{C}$ at the tank outlet. 


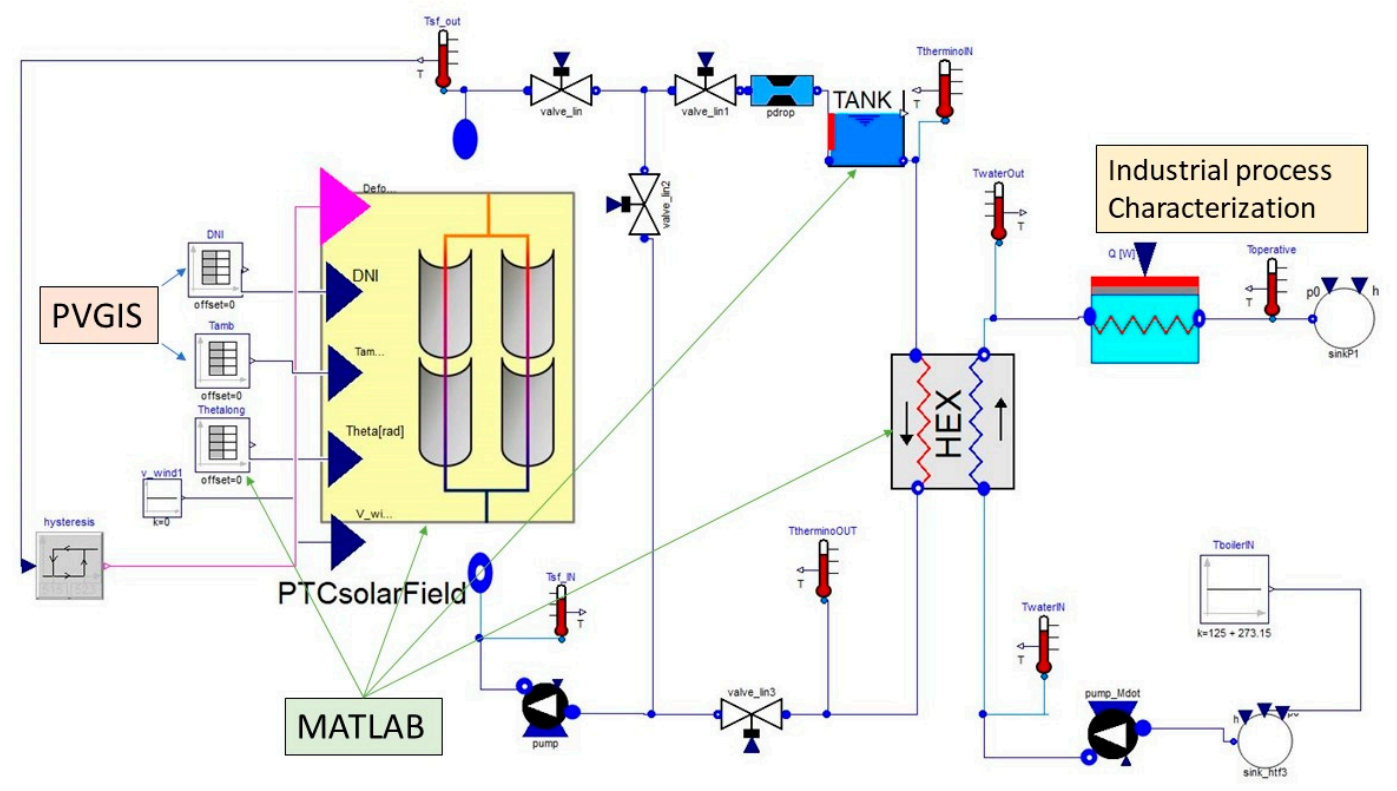

Figure 4. Dynamic simulation scheme.

\section{Results}

Matlab $^{\circledR}$ was used to process the hourly data of solar radiation and climatic temperature (estimating the heat production and the components of IAM for the three different solar collectors) to size the heat exchangers (geometry, heat transfer coefficients and metal mass) and to evaluate the mass flow rate working conditions. In the second step, Dymola ${ }^{\circledR}$ was used to monitor temperature transients and simulate the activity of the solar field in a predictive mode. The available space of the pasta factory is of $2000 \mathrm{~m}^{2}$. The yearly thermal energy produced by the solar field with the three technology in Molina and in Predazzo and the space required to totally cover the heat demand of the pasta factory using only solar energy (100\% RES) are shown in Table 4 . To satisfy $100 \%$ of the thermal demand by solar heat, it is necessary to produce at least $6.69 \mathrm{GWh} /$ year to be combined with an adequate thermal storage to satisfy the daily and seasonal variability. The study of the thermal storage solution is not an aim of this work.

Table 4. Yearly thermal energy production in Molina and in Palermo.

\begin{tabular}{ccccc}
\hline Location & \multicolumn{2}{c}{ Molina } & \multicolumn{2}{c}{ Palermo } \\
\hline $\begin{array}{c}\text { Gross Solar } \\
\text { Field Area }\end{array}$ & $\begin{array}{c}2000 \mathrm{~m}^{2} \text { (Available } \\
\text { space) }\end{array}$ & $\begin{array}{c}27710 \mathrm{~m}^{2}(100 \% \\
\text { solar e.) }\end{array}$ & $\begin{array}{c}2000 \mathrm{~m}^{2} \text { (Available } \\
\text { space) }\end{array}$ & $\begin{array}{c}13300 \mathrm{~m}^{2}(100 \% \\
\text { solar e. })\end{array}$ \\
\hline Type of & \multicolumn{2}{c}{ Qth (GWh/year) } & \multicolumn{2}{c}{ Qth $(\mathrm{GWh} /$ year) } \\
Collectors & 0.341 & 4.75 & 0.73 & 4.91 \\
\hline PTC & 0.441 & $\mathbf{6 . 6 9}$ & 0.93 & $\mathbf{6 . 6 9}$ \\
LFR & 0.211 & 2.93 & 0.52 & 3.42 \\
CPC & & & &
\end{tabular}

Table 4 shows that in order to cover $100 \%$ of the thermal energy demand of industrial processes, $27,710 \mathrm{~m}^{2}$ of available space is necessary in Molina and 13,310 $\mathrm{m}^{2}$ in Palermo. It is useful to notice that the LFR collectors are the technology that produces more thermal energy in one year in both locations. In the available space of the Felicetti pasta factory $\left(2000 \mathrm{~m}^{2}\right)$, the LFR collectors are able to provide $0.341 \mathrm{GWh} /$ year of solar heat in Molina and $0.73 \mathrm{GWh} /$ year in Palermo.

In general, there is an increase in production in Palermo when compared to Molina of about 53\% for PTC, $52 \%$ for LFR and $41 \%$ for CPC technology. Moreover, considering the same location, the LFR can produce $22 \%$ more than PTC and $53 \%$ more than CPC. 
In Figure 5, it is possible to observe the yearly thermal energy production trend for the three solar collector technologies in the function of the gross area used: $2000 \mathrm{~m}^{2}, 13,000 \mathrm{~m}^{2}$, and $27,000 \mathrm{~m}^{2}$.

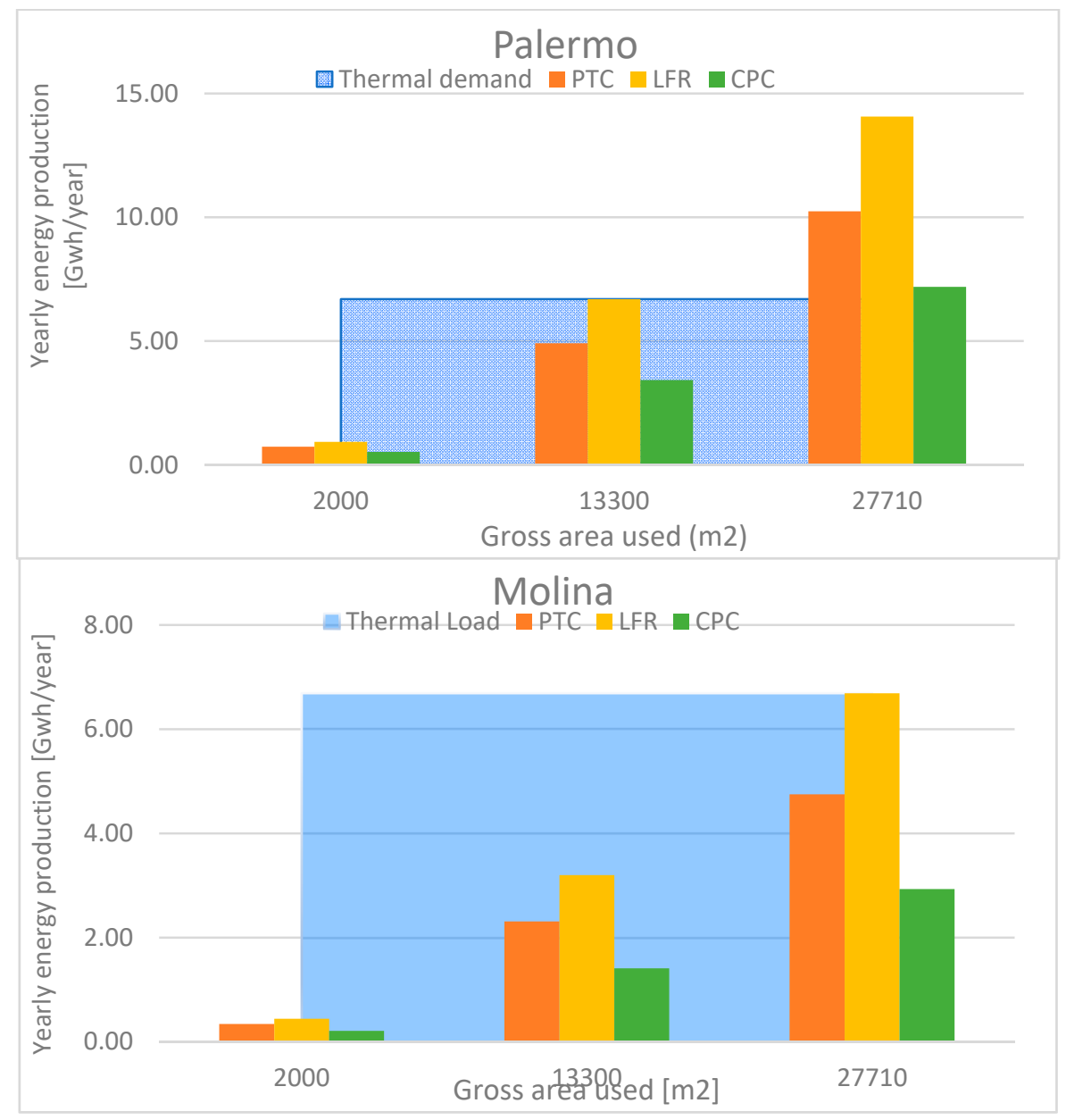

Figure 5. Yearly thermal production in the function of the gross area used in Palermo (above) and in Moline (below).

Almost 52\% more available gross area is required in Molina, and with the available space of 27,710 in Palermo, it is possible to produce thermal energy of about $14 \mathrm{GWh} /$ year.

Finally, a typical day of 21st June was simulated in both locations, using Dymola. Then, a timestep simulation of one minute was carried out in order to assess the transient behavior of the solar field. The solar field is composed of 18 PTC collectors. The number was calculated considering the available surface of the pasta factory of $2000 \mathrm{~m}^{2}$. In Figure 6, the inlet and outlet temperature of the solar field and outlet temperature of tank considering the HTF loop (Thermino SP) are shown. It is possible to see the effect of a cloud passing between 9 a.m. and 10 a.m. and at around 1 p.m., during which time the decrease in DNI causes a change in the pump flow rate and recirculation conditions. As a consequence, the inlet and outlet solar field temperatures of HTF drop at a $136{ }^{\circ} \mathrm{C}$, while the HTF temperature at the outlet of the tank decreases only to $163^{\circ} \mathrm{C}$. 


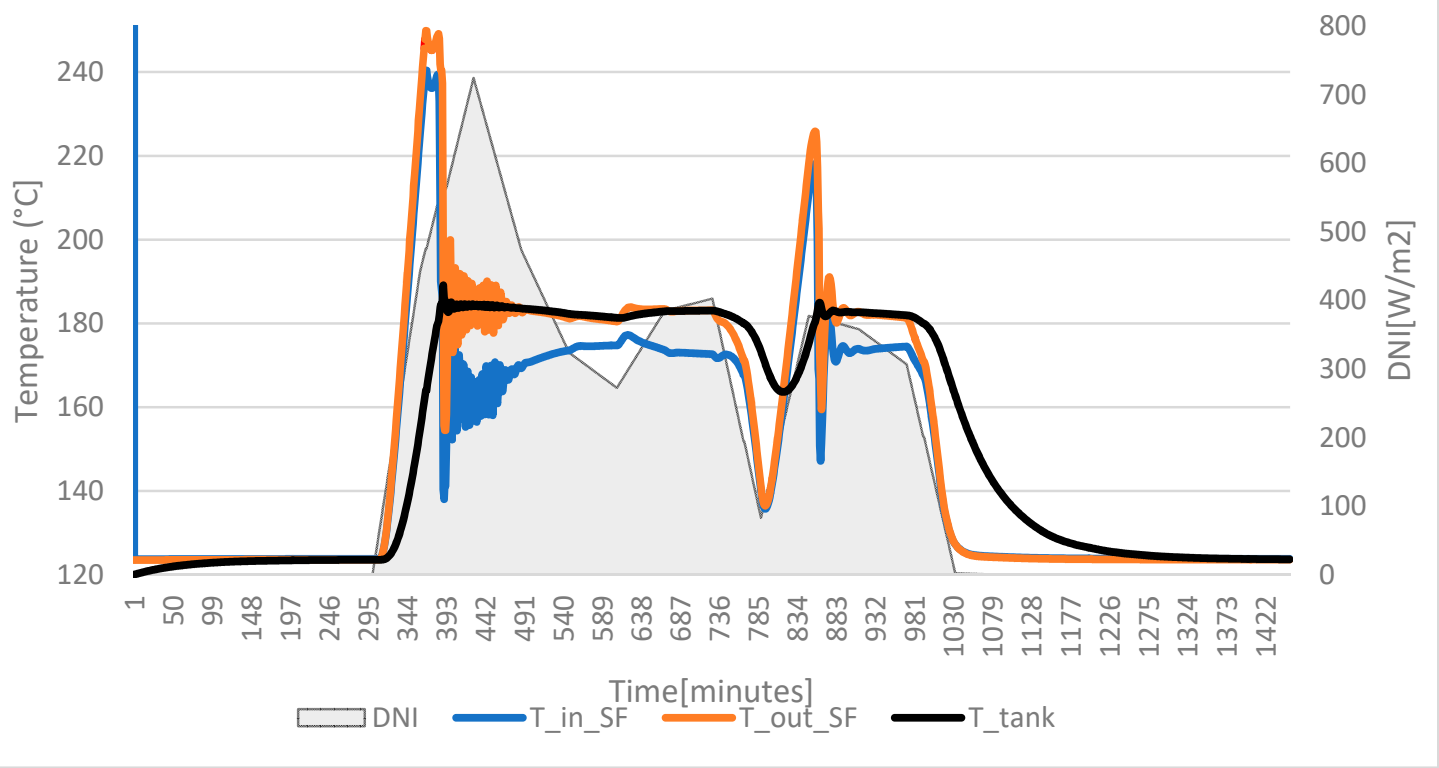

Figure 6. One-minute simulation of temperature trends of HTF (the inlet and outlet temperature of the solar field and the outlet temperature of the tank) considering the day of 21st June in Molina.

It is possible to notice that the maximum temperature reached by the HTF Therminol SP is under $250^{\circ} \mathrm{C}$ and is in accordance with the operating conditions to ensure a certain durability, as expressed in the related datasheet of the commercial product. The black line is the trend of the HTF at the tank outlet. Differently from the temperature trend of the solar field input (blue) and output (orange), the variations due to flow rate tuning and PID operation are reduced due to the thermal inertia induced by a tank that acts as a buffer to variations and to the DNI intermittences.

Figure 7 shows the trend of thermal power of the solar field made up of the same numbers of PTC collectors. In orange is the thermal power related to the location of Palermo, while in blue is that related to the location of Molina. Furthermore, the difference of DNI between Palermo and Molina is also shown. Thus, it is possible to see that when this difference is equal to zero, as observed at around 7 a.m. (424 min), the thermal powers have the same value (about $440 \mathrm{~kW}$ ).

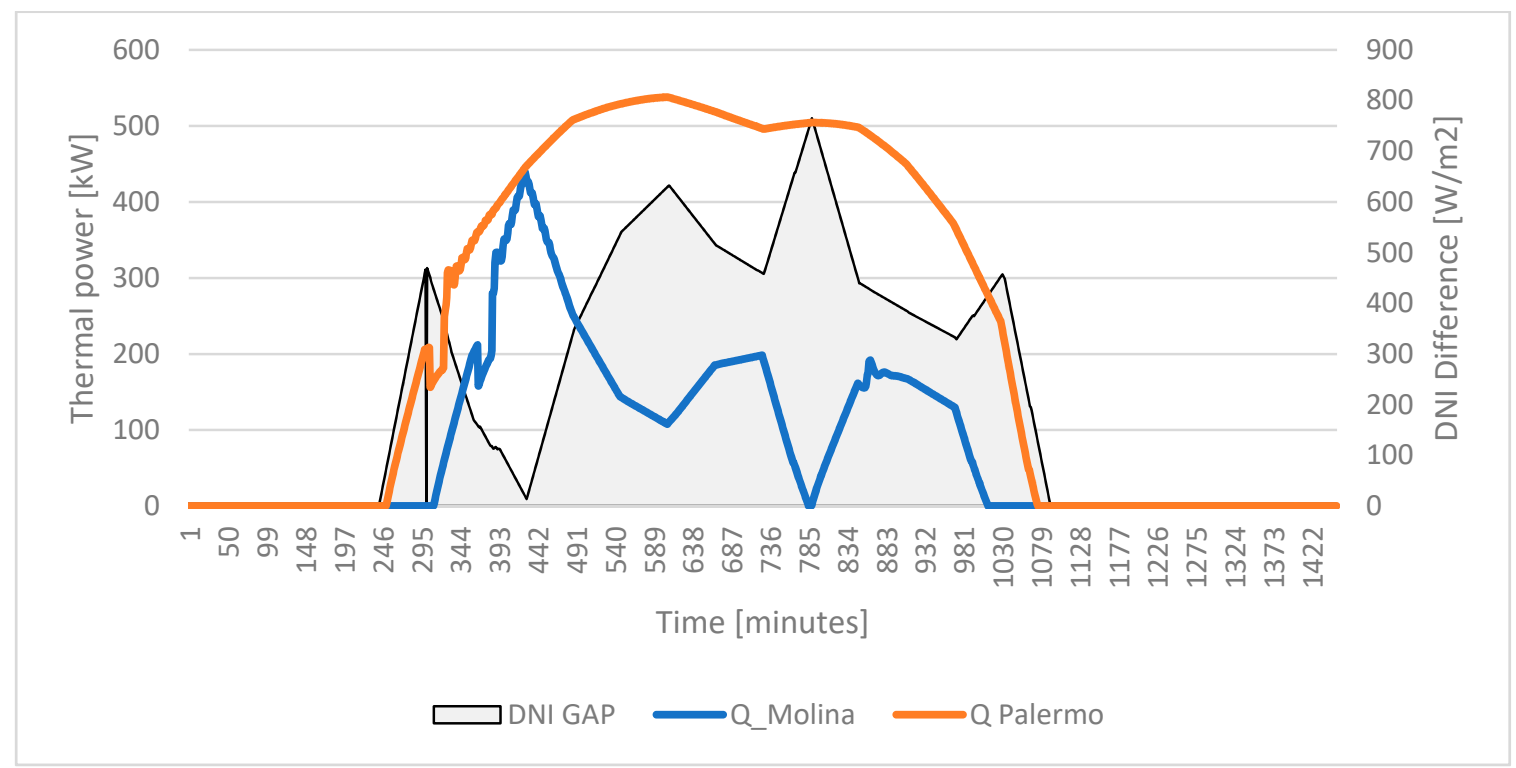

Figure 7. One-minute simulation of thermal power trends in Palermo and in Molina and the DNI trend, respectively. 


\section{Discussion}

The main objective of this paper was to evaluate the integration of solar thermal power into a generic industrial process. As an example, the pasta-drying process of the Felicetti pasta factory was chosen as a case study. A flexible methodology was adopted, in which to make the analysis, it is possible to choose any geographical location and any industrial process. The methodology was based on the joint use of different programs and datasheets and data that provide information on geographical and process coordinates, such as operating temperature, working cycle and flow rate. It has been shown that solar thermal integration works differently with the different solar technologies considered, even in geographically complex contexts, and can play a key role in the massive decarbonization of industrial processes. In fact, the carbon-free solution, found with the integration of $100 \%$ of solar thermal power, makes it possible to avoid an emission of about 1500 tons of $\mathrm{CO}_{2}$ /year. In order to decarbonize the industrial drying process of pasta completely with solar heat, the needed available space in Molina is $27,710 \mathrm{~m}^{2}$, while in Palermo, it is $13,300 \mathrm{~m}^{2}$. Moreover, in the pasta factory's available space of $2000 \mathrm{~m}^{2}$, in Molina, 99 tons of $\mathrm{CO}_{2} /$ year are avoided with LFR technology, while in Palermo, 208 tons of $\mathrm{CO}_{2} /$ year are avoided. Finally, through the dynamic simulation performed in Dymola, it was possible to verify the behavior of the solar field with sudden cloud shading. The clouds determine the sudden decrease in the DNI, which makes it necessary to use a control system on the pump flow rate and recirculation conditions. It was possible to verify that despite the small size of the HTF tank, it is possible to reach and to maintain the temperature required by the industrial process by appropriately tuning the flow rate and recirculation. Furthermore, it can be noted that the geographical location and topography have a significant influence on DNI and thermal production. In particular in Figure 6, it is possible to observe that with the decrease in the DNI to $140 \mathrm{w} / \mathrm{m} 2$, it is possible to bring the amount of thermal power produced by the solar field to zero. In regard to the one-minute simulation on 21st June in Palermo, there is a peak thermal power of $536 \mathrm{KW}$ with a solar fraction of $83 \%$, while in Molina, there is a peak of thermal power of $439 \mathrm{Kw}$ with a solar fraction of $67 \%$.

Acknowledgments: The work here proposed is part of the INSHIP project (Integrating National Research Agendas on Solar Heat for Industrial Processes). This project has received funding from the European Union's Horizon 2020 research and innovation programme LCE-ECRIA-European Common Research Innovation Agenda under the grant agreement INSHIP No 731287, engaging major European research institutes such as FBK in Trento, with recognized activities of SHIP (Solar heat for Industrial Processes). The work is also in collaboration with the "Felicetti Pasta Factory", which contributed to the work in providing relevant data for the presented analysis, and with prof. M. Grigiante of Unitn (University of Trento) who supported the methodological approach.

\section{References}

1. Jackson, R.B.; Le Quéré, C.; Andrew, R.M.; Canadell, J.G.; Korsbakken, J.I.; Liu, Z.; Peters, G.P.; Zheng, B. Global energy growth is outpacing decarbonization. Environ. Res. Lett. 2018, 13, 120401, doi:10.1088/17489326/aaf303.

2. Martins, F.; Felgueiras, C.; Smitkova, M.; Caetano, N. Analysis of Fossil Fuel Energy Consumption and Environmental Impacts in European Countries. Energies 2019, 12, 964, doi:10.3390/en12060964.

3. IEA. World Energy Balances; IEA: Paris, France, 2019.

4. Barberis, S.; Peccianti, F.; Castellino, L.; Bolognesi, T.; Bortoletto, A. \{SHIP\}2FAIR Martini \& Rossi: Integration of Solar Heat in Industrial Process Preliminary evaluation. E3S Web Conf. 2019, 113, 3018, doi:10.1051/e3sconf/201911303018.

5. Tuller, H.L. Solar to fuels conversion technologies: A perspective. Mater. Renew. Sustain. Energy 2017, 6, doi:10.1007/s40243-017-0088-2.

6. Kalogirou, S.A. Solar thermal collectors and applications. Prog. Energy Combust. Sci. 2004, 30, 231-295, doi:10.1016/j.pecs.2004.02.001.

7. Kalogirou, S. The potential of solar industrial process heat applications. Appl. Energy 2003, 76, 337-361, doi:10.1016/s0306-2619(02)00176-9.

8. Brunner, C. IEA Task 49; 2015. Available online: https://task49.iea-shc.org/ (accessed on 28 February 2020). 
9. Eurostat Consumption of Energy. 2014. Available online: http://ec.europa.eu (accessed on 28 February 2020).

10. Database for Solar Heat Plants. Available online: http://ship-plants.info/ (accessed on 28 February 2020).

11. Banout, J. Solar Drying Systems. In Solar Drying Technology; Springer: Singapore, 2017; pp. 39-67.

12. Fudholi, A.; Ridwan, A.; Yendra, R.; Desvina, A.P.; Hartono, H.; Ali, M.K.B.M.; Suyono, T.; Sopian, K. Solar Drying Technology in Indonesia: An Overview. Int. J. Power Electron. Drive Syst. 2018, 9, 1804, doi:10.11591/ijpeds.v9.i4.pp1804-1813.

13. Buscemi, A.; Panno, D.; Ciulla, G.; Beccali, M.; Brano, V. Lo Concrete thermal energy storage for linear Fresnel collectors: Exploiting the South Mediterranean's solar potential for agri-food processes. Energy Convers. Manag. 2018, 166, 719-734, doi:10.1016/j.enconman.2018.04.075.

14. Panno, D.; Messineo, A.; Dispenza, A. Cogeneration plant in a pasta factory: Energy saving and environmental benefit. Energy 2007, 32, 746-754, doi:10.1016/j.energy.2006.06.004.

15. Ringeisen, B.; Barrett, D.M.; Stroeve, P. Concentrated solar drying of tomatoes. Energy Sustain. Dev. 2014, 19, 47-55, doi:10.1016/j.esd.2013.11.006.

16. Bououd, M.; Hachchadi, O.; Janusevicius, K.; Mechaqrane, A.; Martinaitis, V. Energy performance of a clay tiles solar drying system. In AIP Conference Proceedings; AIP Publishing LLC: New York, NY, USA, 2018.

17. Cotrado, M.; Dalibard, A.; Söll, R.; Pietruschka, D. Design, Control and First Monitoring Data of a Large Scale Solar Plant at the Meat Factory Berger, Austria. Energy Procedia 2014, 48, 1144-1151, doi:10.1016/j.egypro.2014.02.129.

18. Desai, D.D.; Raol, J.B.; Patel, S.; Chauhan, I. Application of Solar energy for sustainable Dairy Development. Eur. J. Sustain. Dev. 2013, 2, 131-140, doi:10.14207/ejsd.2013.v2n2p131.

19. European Commission. Photovoltaic Geographical Information System. Available online: https://re.jrc.ec.europa.eu/pvg_tools/it/tools.html (accessed on 28 February 2020).

20. S. PTMx18. Available online: https://www.soltigua.com/it/ptmx-introduction/ (accessed on 28 February 2020).

21. L.F. LF-11. Available online: https://www.industrial-solar.de/ (accessed on 28 February 2020).

22. K.S.C.P.C. 58. Available online: http://www.kloben.it (accessed on 28 February 2020).

23. Z. G. Appunti di tecnologia della pasta. Available online: http://www.giuseppezeppa.com/files/tecnologiapasta-giu-17.pdf (accessed on 28 February 2020).

24. Mattarolo, A.C.C.B.L. Trasmissione del Calore; Cleup Editore: 1992.

25. Bellos, E.; Tzivanidis, C.; Antonopoulos, K.A. A detailed working fluid investigation for solar parabolic trough collectors. Appl. Therm. Eng. 2017, 114, 374-386, doi:10.1016/j.applthermaleng.2016.11.201.

26. Therminol SP. Available online: https://www.therminol.com/product/71093454 (accessed on 28 February 2020).

(C) 2020 by the authors. Licensee MDPI, Basel, Switzerland. This article is an open access article distributed under the terms and conditions of the Creative Commons Attribution (CC BY) license (http://creativecommons.org/licenses/by/4.0/). 